\title{
Short Communication: Social Stress and Immunoregulation
}

\author{
Mohamad Reza Vaez Mahdavi ${ }^{*}$ (D) \\ 1. Department of Physiology, Shahed University, Tehran, Iran.
}

Citation Vaez Mahdavi MR. Social Stress and Immunoregulation. Immunoregulation. 2018; 1(1):3-4. http://dx.doi. org/10.32598/Immunoregulation.1.1.3

doi: : http://dx.doi.org/10.32598/Immunoregulation.1.1.3

$\mathbf{Q}$

ualified and healthy lifestyle consists of extensive broad dimensions of physical health, resistance against diseases, fast recovery following disease, better social communications, flexibility in facing social problems, better education, better interactions, stress management, transcendental individual and social behavior, as well as morality. A variety of the contemporary academic studies and scientific findings secure emphases on the effects of environmental conditions and social policies on community mental function and cognitive proficiency related processes in healthy lifestyle formation.

Environmental conditions and social status have been infered to have roles in mental and neural development both via effects on access to social services and by means of the effectiveness of social stress, inequalities and discrimination, deprivations, etc. on physical and mentalcognitive functions. The effect of environmental factors can extend to various neuronal transmissions beyond genetic features. Brain areas involved in reasoning and problem-solving skill may directly be influenced by socio-economic circumstances. The role of early childhood stages in this development is well established. There is clear evidence that exposure of children to cold winters in England led to social disorder in their adulthood [1].

As indicated in Marmot Review, psycho-social circumstances and stresses in early childhood stages play an un- deniable role in the formation of cognitive and cerebral development $[2,3]$.

Experimental evidence has depicted the role of social stresses through various effects on different glucocorticoid and mineralocorticoid receptors in different brain areas [2]. These different effects are followed by varying levels of post-stress cerebral inflammation, which leads to disorders in the functions of cerebral-psychic-behavioral operation mechanisms of stress in the brain [4].

Our experimental animal studies have shown lipofuscin accumulation in heart following induced stress by exposure to social inequalities [5]. Appearance of this predisposing pigment to premature aging, which could accelerate chronic heart failure in animals exposed to social stress, was confirmed by electron microscopy images [6]. The results obtained in our studies also demonstrated the impact of social stress on memory decline [7], acute and chronic pain [8], anxiety [9], cardiac hemodynamic [3], liver disorders [10], cellular apoptosis [11], processes elicited by oxidative stress [12], proinflammatory mediators, and cytokine levels. Also, our results have shown development of the various levels of glucocorticoid hormones following exposure to a range of the social stress.

Social stress induces cortisol escape. This phenomenon leads to long-term effects of the hypercorticoidism through simultaneous rise in cortisol together with in-

* Corresponding Author:

Mohamadreza Vaez Mahdavi, PhD.

Address: Department of Physiology, Shahed University, Tehran, Iran.

Phone: +98 (21) 33114749

E-mail:vaezmahdavi@shahed.ac.ir 
crease in Corticotropin-Releasing Hormone and Adrenocorticotropic Hormone levels, Increased blood sugar and susceptibility to diabetes mellitus, increased cholesterol level, and cholesterol plaque via effect on mineralocorticoid and glucocorticoid receptors bring about various behavioral effects.

Psychosomatization disorder is only one of the related signs in this area. Many of the worthy international studies stress on the fact that atherosclerosis, metabolic syndrome, immunosupression and contraction of infectious and microbial diseases are only a part of the problems which can occur following chronic stress exposure. Chronic social stress with slight but longstanding increase in glucocorticoid and development of the cortisol escape phenomenon leads to longtime humoral immune deficiency and subsequently via caspases reduction causes impairment of the systems coping with misplaced mutations and, as a result, predisposes organism to abnormal cell proliferation and finally different types of cancer. The studies mentioned are warnings to policy makers regarding the significant neurodevelopmental effects of the social policies in the macro level.

Considering the above mentioned findings, one of the main and central roles of the acute and chronic social stress is dysregulation of the immune responses and subsequent related effects. With regards to the importance of immunoregulation in maintenance of human heath, prevention of diseases, treatment and management of diseases, paying attention to the role of social stress, and discovery of the possible solutions for prevention of these deteriorating effects seem to be extremely crucial. Hence, this issue is one of the priority research topics in this journal and we welcome valuable manuscripts in this field.

\section{References}

[1] Barnes M, Butt S, Tomaszewski W. The dynamics of bad housing: The impact of bad housing on the living standards of children. London: National Centre for Social Research London; 2008.

[2] Marmot MG, Allen J, Goldblatt P, Boyce T, McNeish D, Grady M, et al. Fair society, healthy lives: Strategic review of health inequalities in England post-2010; 2010.

[3] R Sz. Effect of regular exercise on consequences of chronic psycho-social stress in isoproterenol induced heart failure in rat; 2016.

[4] McEwen BS, Gianaros PJ. Stress-and allostasis-induced brain plasticity. Annual Review of Medicine. 2011; 62:431-45. [DOI:10.1146/annurev-med-052209-100430] [PMID] [PMCID]
[5] Heidary F, Mahdavi MRV, Momeni F, Minaii B, Rogani M, Fallah N, et al. Food inequality negatively impacts cardiac health in rabbits. Plos one. 2008; 3(11):e3705. [DOI:10.1371/ journal.pone.0003705] [PMID] [PMCID]

[6] Vaez MM, Mojarab S, Tarihi T, Roghani M, Faghihzadeh S, Hasanpour EM. The effect of food deprivation, social status and inequality on myocardial cell damage in male rabbits; 2010.

[7] Mahdavi V, Reza M, Roghani M, Khalili M, Dalir R. The effect of food restriction on learning and memory of male Wistar rats: A behavioral analysis. Basic and Clinical Neuroscience. 2010; 1(2):20-3.

[8] Aghajani M, Mahdavi V, Reza M, Ghazanfari T, Khalili $\mathrm{M}$, Azimi A, et al. Effects of social stress on pain behavior immune cells and serum concentrations of TNF-a, Interleukin-1 and Interleukin-6 in female mice. Physiology and Pharmacology. 2012; 15(4):545-61.

[9] Rezaei S, Vaez MMR, Noorbala AA, Roghani M, Faghihzadeh S. Effect of food restriction, food deprivation and food ine-quality on anxiety-like behavior in rats; 2014.

[10] Moradi F, Mahdavi V, Reza M, Ahmadiani A, Roghani M, Altarihi T, et al. Unstable social situation and food inequality can promote accumulation of lipofuscin and induced apoptosis in hepatocytes. Koomesh. 2012; 14(1):55-64.

[11] Moradi F, Mahdavi MRV, Ahmadiani A, Rogani M, Delshad AR, MojarabS, et al. Social instability, food deprivation and food inequality can promote accumulation of lipofuscin and induced apoptosis in hepatocytes. World Applied Sciences Journal. 2012; 20(2):310-8.

[12] Mahdi Dust S, Mahdavi V, Reza M, Kabudanian Ardestani S, Sedaghat R, Jalilvand F, et al. Effect of stress due to food deprivation, social inequality and instability on brain. Physiology and Pharmacology. 2013; 16(4):350-9. 